\title{
Determination of royal jelly freshness by ELISA with a highly specific anti-apalbumin 1, major royal jelly protein 1 antibody*
}

\author{
Li-rong SHEN ${ }^{\dagger}$, Yi-ran WANG, Liang ZHAI, Wen-xiu ZHOU, \\ Liang-liang TAN, Mei-lu LI, Dan-dan LIU, Fa XIAO \\ (Zhejiang Key Laboratory for Agro-Food Processing, Fuli Institute of Food Science, Department of Food Science and Nutrition, \\ Zhejiang University, Hangzhou 310058, China) \\ †E-mail: shenlirong@zju.edu.cn
}

Received Aug. 17, 2014; Revision accepted Sept. 21, 2014; Crosschecked Jan. 8, 2015

\begin{abstract}
Major royal jelly protein 1 (MRJP1), designated apalbumin 1, has been regarded as a freshness marker of royal jelly (RJ). A MRJP1-specific peptide (IKEALPHVPIFD) identified by bioinformatics analysis of homologous members of the major royal protein family was synthesized and used to raise polyclonal anti-MRJP1 antibody (antiSP-MRJP1 antibody). Western blot analysis showed that anti-SP-MRJP1 antibody only reacted with MRJP1 in RJ. In contrast, the previously reported antibody against recombinant MRJP1 (anti-R-MRJP1 antibody) reacted with other members of MRJP family in RJ. Enzyme-linked immunosorbent assay (ELISA) using anti-SP-MRJP1 antibody demonstrated that MRJP1 content in RJ stored at $40{ }^{\circ} \mathrm{C}$ significantly degraded by $37.3 \%, 55.9 \%, 58.0 \%, 60.6 \%$, $65.7 \%, 72.7 \%$, and $73.1 \%$ at $7,14,21,28,35,42$, and $49 \mathrm{~d}$, respectively, when compared with MRJP1 content in fresh RJ $(0$ d). Optical density analysis of MRJP bands from sodium dodecyl sulfate-polyacrylamide gel electrophoresis (SDS-PAGE) profiles demonstrated that the degradation of MRJP1, MRJP2, MRJP3, and MRJP5 in RJ was strongly and positively correlated with the period of storage $(P<0.0001)$. Our results indicated anti-SP-MRJP1 antibody was highly specific for MRJP1, and ELISA using the antibody is a sensitive and easy-to-use method to determine the freshness and authenticity of RJ.
\end{abstract}

Key words: Freshness, Royal jelly, Major royal jelly protein 1 (MRJP1), Enzyme-linked immunosorbent assay (ELISA), High specific antibody

doi: 10.1631 jzus.B1400223

Document code: A

CLC number: S896.8

\section{Introduction}

Royal jelly (RJ) is secreted by nurse honeybees from the hypopharyngeal and mandibular glands. This key nutrient, food for all young larvae, is vital in caste determination, development, and reproduction of the queen (Salazar-Olivo and Paz-Gonzales, 2005).

\footnotetext{
* Project supported by the Public Beneficial Scientific \& Technical Plan of Zhejiang (No. 2011C22039), the Important Scientific \& Technical Plan of Zhejiang (No. 2011C12023), the Important Scientific \& Technical Innovation Project of Hangzhou (No. 20131812A25), the Foundation of Fuli Institute of Food Science of Zhejiang University (No. KY201404), and the National Natural Science Foundation of China (No. 31271848)

(D) ORCID: Li-rong SHEN, http://orcid.org/0000-0002-3197-9245

(c) Zhejiang University and Springer-Verlag Berlin Heidelberg 2015
}

Previous studies have demonstrated a wide range of health benefits to humans and model organisms, including vasodilative and hypotensive activities (Tokunaga et al., 2004), antitumor (Tamura et al., 1987), anti-inflammatory (Fujii et al., 1990; Kohno et al., 2004), antibacterial and disinfectant properties (Fujiwara et al., 1990; Shen et al., 2010a), antifatigue activity (Kamakura et al., 2001a), and increasing the average lifespan in mice (Inoue et al., 2003) and nematodes (Honda et al., 2011). Because of its great potential benefits to human health, $\mathrm{RJ}$ is widely used as a key component in many commercial products including medicine, dietary supplements, and cosmetics (Kamakura et al., 2001c). Thus, an easy-to-use and reliable method for the qualitative 
and quantitative evaluation of commercially available $\mathrm{RJ}$ products is needed. $\mathrm{RJ}$ contains $12 \%-15 \%$ protein, of which $80 \%$ belongs to soluble RJ proteins, the major RJ protein (MRJP) family (Howe et al., 1985; Simúth, 2001). Nine members of MRJP (MRJP1-9) have been reported; among them five (MRJP1-5) make up $82 \%$ of the total RJ protein content (Schmitzová et al., 1998; Malecová et al., 2003; Albert and Klaudiny, 2004; Drapeau et al., 2006; Shen et al., 2010b). MRJP1, designated as apalbumin 1, constitutes $45 \%$ of water-soluble proteins and is the most abundant protein in RJ (Furusawa et al., 2008). It is a glycoprotein of 432 amino acid residues with a molecular weight of 55-57 kDa (Hanes and Simúth, 1992; Shen et al., 2010b). MRJP1, in the form of an oligomeric complex, has more biological functions than its nutritional role in the larval development of honeybees. It is expressed in the brain mushroom bodies and nervous system of the adult (Peixoto et al., 2009). Previously designated as royalactin, it was recently found to induce the differentiation of honeybee larvae into queens through an epidermal growth factor receptor (EGFR)-mediated signaling pathway. Royalactin is a special factor for increasing body size, promoting ovary growth and shortening developmental time in both honeybees and Drosophila melanogaster (Kamakura, 2011). Moreover, MRJP1 was also demonstrated to have various biological functions in different model organisms in addition to its anti-fatigue effect in mice (Kamakura et al., 2001a). MRJP1 stimulates rat hepatocyte DNA synthesis, prolongs the proliferation of hepatocytes, increases albumin production (Kamakura et al., 2001b), and regulates mouse macrophages to release tumor necrosis factor $\alpha$ (TNF- $\alpha$ ) (Majtan et al., 2006). Peptides derived from MRJP1 by enzymatic hydrolysis in the gastrointestinal tract possess potent antihypertensive activity in rats (Matsui et al., 2002). Furthermore, the C-terminal of MRJP1 may be a precursor of the antimicrobial peptides known as Jelleines (Fontana et al., 2004).

MRJP1 was suggested as a marker for the freshness of RJ because the degradation of this protein was especially associated with its storage temperature and storage period (Kamakura et al., 2001c). Currently, 10-hydroxy-2-decenoic acid (10-HDA), which is found only in RJ, has been used as the typical quality criterion of RJ. However, its content changes little during storage at $40{ }^{\circ} \mathrm{C}$ for one week (Kamakura et al., 2001c; Sabatini et al., 2009). As no correlation between 10-HDA content and storage duration was found whatever the storage temperature, new criteria to measure the freshness in the duration of RJ storage are needed (Antinelli et al., 2003).

High performance liquid chromatography (HPLC) analysis of MRJP1 separated from RJ with column chromatography has been used primarily as the standard method to determine the content of MRJP1 in RJ (Kamakura et al., 2001c). Recently, enzymelinked immunosorbent assay (ELISA) using purified MRJP1 with polyclonal antibody against recombinant MRJP1 expressed in Escherichia coli (anti-R-MRJP1 antibody) has been developed to measure MRJP1 in honey (Bíliková and Simúth, 2010). However, the polyclonal antibody against the recombinant MRJP1 is unsuitable for determining the content of MRJP1 in $R J$ because the quantification reflects the total amount of MRJP family members, which share a common evolutionary ancestor of the yellow protein from Drosophilia melanogaster (Albert et al., 1999). Therefore, more recently, a new method using a polyclonal antibody with a synthesized peptide (C+SGEYDYKNNYPSDID) specific for MRJP1 for the determination of $\mathrm{RJ}$ freshness was developed (Yamaguchi et al., 2013).

In this study, we have identified a specific MRJP1 peptide via bioinformatics analysis of amino acid sequences of homologous members of the MRJP family, and generated a new MRJP1 antibody specific for MRJP1. Our results demonstrated that this new molecule, anti-SP-MRJP1 antibody, binds more specifically and sensitively to MRJP1 than previously reported anti-R-MRJP1 antibody. Using ELISA with this antibody, we accurately detected the degradation of MRJP1 in RJ during storage at high temperature. Our ELISA method with anti-SP-MRJP1 antibody will be more applicable for quality control and authenticity identification of $\mathrm{RJ}$ in production and commerce around the world.

\section{Materials and methods}

\subsection{Reagents}

$\mathrm{RJ}$ from the western honeybee (Apis mellifera) was harvested $72 \mathrm{~h}$ after seeding young $(1 \mathrm{~d}$ old $)$ 
larvae from an apiary provided by the Hangzhou Biyutian Health Food Corporation, Ltd. (Tonglu County, Zhejiang, China) and then was stored at $-20{ }^{\circ} \mathrm{C}$ (Yamaguchi et al., 2013). Diaminobenzidine (DAB) and goat anti-rabbit IgG-linked horseradish peroxidase (IgG/HRP) were purchased from Boster Biological Technology, Ltd. (Wuhan, China). Protein molecular weight standard was purchased from TaKaRa (Dalian, China). Nitrocellulose membranes (NCs) were purchased from Millipore (Billerica, MA, USA). CNBr-activated Sepharose 4B was purchased from GE (NY, USA). Sulfosuccinimidyl-4-( $N$-maleimidomethyl) cyclohexane-1-carboxylate (Sulfo-SMCC), keyhole limpet hemocyanin (KLH), and SulfoLink Resin were from Pierce (Appleton, WI, USA).

\subsection{Homology analysis of MRJP sequences and specific peptide synthesis}

The complete amino acid sequences of nine members of the MRJP family in the honeybee were acquired from GenBank web (http://www.ncbi.nlm. nih.gov). These MRJP sequences were aligned using Genetyx-Win Version 5 (Software Development Co., Tokyo, Japan). The unique peptide regions with more than three amino acid residues specific for MRJP1 were selected as the highly specific peptide region. A specific peptide that corresponds to the selected region was synthesized using the AMS 422 robot (ABIMED GmbH, Langenfield, Germany) by China Peptides Co., Ltd.

\subsection{Preparation of polyclonal antibodies against MRJP1}

The polyclonal anti-R-MRJP1 antibody was previously obtained by immunization of male New Zealand White rabbits with a recombinant MRJP1 expressed in E. coli in our laboratory (Shen et al., 2010b). The anti-R-MRJP1 antibody was purified to homogeneity by HPLC, and was then conjugated to the amino groups of KLH, a carrier protein through the thiol group of the terminal cysteine residue for immunization of male rabbits to generate anti-SPMRJP1 antibody. Briefly, three intradermal injections of KLH-coupled regional peptide of MRJP1 (KLHpeptide) to male New Zealand white rabbits at three-week intervals were followed by two subcutaneous injections of the antigen dissolved in complete Freund's adjuvant (Majtan et al., 2006). The same purified specific synthetic peptide was conjugated to the amino acid of bovine serum albumin (BSA), a carrier protein through the sulfhydryl group of the terminal cysteine residue for preparation of antigen (BSA-peptide) affinity column and detection of binding activity to anti-SP-MRJP1 antibody as the antigen.

\subsection{Purification and binding activity assay of anti- SP-MRJP1 antibody}

Anti-SP-MRJP1 antibody was purified with antigen affinity column filled with SulfoLink Resin conjugated to BSA-peptide. The column was washed with 10 volumes of phosphate-buffered saline (PBS). The rabbit serum was filled with a Millex-GV $0.45 \mu \mathrm{m}$ filter, loaded onto the column, and then washed with PBS. The purified antibody was eluted with buffer $(7.5 \%(0.075 \mathrm{~g} / \mathrm{ml})$ of glycine, $\mathrm{pH} 2.7)$, then dialyzed with deionized water $\left(\mathrm{ddH}_{2} \mathrm{O}\right)$. The titer of antiSP-MRJP1 antibody to react with BSA-peptide was measured with ELISA (see Section 2.8).

\subsection{Preparation of antibody column and purifi- cation of MRJP1}

CNBr-activated Sepharose 4B was dissolved in $1 \mathrm{mmol} / \mathrm{L} \mathrm{HCl}$ solution before the purified anti-SPMRJP1 antibody was added. The mixture was then added to an affinity column and incubated overnight at $4{ }^{\circ} \mathrm{C}$. In order to purify MRJP1, $10 \mathrm{~g}$ of fresh RJ was dissolved in $10 \mathrm{ml}$ of $\mathrm{ddH}_{2} \mathrm{O}$ and vortexed. Then, RJ was ultracentrifuged (CP70MX Ultracentrifuge, Hitachi, Japan) at 245000g (Simúth, 2001), and placed on anti-SP-MRJP1 antibody affinity column for $2 \mathrm{~h}$. The column was washed with 3 volumes of normal saline $(0.9 \%(9 \mathrm{~g} / \mathrm{L})$ of $\mathrm{NaCl})$ to remove unbound proteins. The native MRJP1 was eluted with $2 \mathrm{ml}$ elution buffer ( $\mathrm{pH} 3, \mathrm{ddH}_{2} \mathrm{O}$ ), analyzed by sodium dodecyl sulfate polyacrylamide gel electrophoresis (SDS-PAGE), and freeze-dried and stored at $-20{ }^{\circ} \mathrm{C}$. The purified MRJP1 was then freeze-dried and stored at $-20^{\circ} \mathrm{C}$.

\subsection{SDS-PAGE and Western blot assay}

To measure the specificity of the antibodies, Western blot analysis was performed using MRJP1 purified from fresh RJ. Eight $\mu \mathrm{g}(15 \mu \mathrm{l})$ of each protein sample was separated by $12 \%$ SDS-PAGE according to the standard method (Sambrook et al., 
1989). After electrophoresis, protein bands on SDSPAGE gels were transferred to $\mathrm{NC}$ for Western blot analysis. The anti-R-MRJP1 antibody and anti-SPMRJP1 antibody were used as the primary antibodies at a dilution from 3000- to 5000-fold, respectively. The goat anti-rabbit IgG/HRP was used as the secondary antibody. The treated $\mathrm{NC}$ was reacted with DAB substrate as described previously (Shen et al., 2010b).

\subsection{Degradation analysis of MRJPs in RJ by gel documentation system}

The protein concentration in $\mathrm{RJ}$ was determined by a total nitrogen Kjeldahl method (AQSIQ, 2008). Fresh RJ samples were dispensed into sterile $50 \mathrm{ml}$ glass bottles. These bottles were then incubated at $40{ }^{\circ} \mathrm{C}$, and were sampled every $7 \mathrm{~d}(0,7,14,21,28$, 35 , and $42 \mathrm{~d}$ ). All samples were stored at $-40{ }^{\circ} \mathrm{C}$ after thermal treatment immediately for SDS-PAGE analysis as previously described (Kamakura et al., 2001c). A total of $15 \mu$ protein samples were analyzed by SDS-PAGE. MRJP bands from SDS-PAGE were quantified using SensiAnsys Quantity Analysis program in the gel documentation system (Shanghai Peiqing Science \& Technology Co., Ltd., China). The differences (relative value, \%) of the optical density (OD) of the MRJP protein band in the object RJ samples $(7,14,21,28,35$, and $42 \mathrm{~d})$ relative to that of the same protein in fresh RJ $(0 \mathrm{~d})$ control were displayed according to the method described by the manufacturer's manual. The OD of the MRJP protein band in fresh RJ (0 d) control was regarded as $100 \%$. Each assay was repeated with at least three independent replicates.

\subsection{Determination of MRJP1 in RJ by ELISA with different antibodies}

Micro-titration plates were coated overnight at $4{ }^{\circ} \mathrm{C}$ with $100 \mu \mathrm{l} /$ well carbonate buffer solution (CBS: $\mathrm{Na}_{2} \mathrm{CO}_{3} 1.59 \mathrm{~g}, \mathrm{NaHCO}_{3} 2.93 \mathrm{~g}, \mathrm{pH}$ 9.6) with 0, 2, 4, 6,8 , and $10 \mu \mathrm{g} / \mathrm{ml}$ of standard MRJP1, and then blocked with $1.5 \%(0.015 \mathrm{~g} / \mathrm{ml})$ dried milk in PBS $(137 \mathrm{mmol} / \mathrm{L} \mathrm{NaCl}, 2.7 \mathrm{mmol} / \mathrm{L} \mathrm{KCl}, 100 \mathrm{mmol} / \mathrm{L}$ $\mathrm{Na}_{2} \mathrm{HPO}_{4}, 2 \mathrm{mmol} / \mathrm{L} \mathrm{KH}_{2} \mathrm{PO}_{4}, \mathrm{pH}$ 7.4). Subsequently, $100 \mu \mathrm{l}$ of anti-SP-MRJP1 antibody and anti-RMRJP1 antibody diluted with $0.1 \%(1 \mathrm{~g} / \mathrm{L})$ dried milk in PBS were added, and incubated in the coated wells for $1.5 \mathrm{~h}$ at $37^{\circ} \mathrm{C}$, respectively. The binding (titer) of
anti-SP-MRJP1 antibody and anti-R-MRJP1 antibody with MRJP1 as antigen was visualized using $100 \mu \mathrm{l}$ of an anti-rabbit IgG conjugated to peroxidase for $1 \mathrm{~h}$ at $37{ }^{\circ} \mathrm{C}$, respectively. The color reaction was initiated by adding $100 \mu \mathrm{l} /$ well of tetramethyl benzidine. The reaction was stopped after $15 \mathrm{~min}$ by adding $2 \mathrm{~mol} / \mathrm{L}$ $\mathrm{H}_{2} \mathrm{SO}_{4}$ to the wells. OD was measured at $450 \mathrm{~nm}$ with an ELISA plate reader. Calibration curves in the concentration range from 0 to $10 \mu \mathrm{g} / \mathrm{ml}$ MRJP1 were generated.

The content of MRJP1 in total RJ protein was measured to quantify the RJ freshness. The calibration curves of MRJP1 in a broad concentration range from 2 to $20 \mathrm{~g} / \mathrm{ml}$ against anti-SP-MRJP1 antibody and anti-R-MRJP1 antibody were prepared in a 96-well plate in PBS separately, corresponding to the MRJP1 content of diluted PBS, and no antigen (MRJP1) was used as the blank control. The ELISA detection for MRJP1 content in fresh RJ samples using anti-SP-MRJP1 antibody and anti-R-MRJP1 antibody was implemented separately. Then, ELISA assay was performed to determine the degradation of MRJP1 in RJ samples from different storage periods $(0,7,14,21,28,35,42$, and $49 \mathrm{~d})$ under $40{ }^{\circ} \mathrm{C}$ with anti-R-MRJP1 and anti-SP-MRJP1 antibodies, respectively. The MRJP1 content of each well was calculated based on its OD value with reference to the calibration curve. Each assay was repeated with at least three independent replicates. For the comparison with the ELISA quantitation, the density values of the MRJP1 bands on SDS-PAGE gel of the RJ samples from different storage periods were generated using ImageJ program (http://rsb.info.nih.gov/ij/index.html).

\subsection{Data processing and statistics}

For ELISA, fitting curves were performed with Microsoft Office Excel 2007. The statistics analysis was carried out with the SPSS 16.0 software (SPSS, Inc., Chicago, IL, USA). One-way analysis of variance (ANOVA) with Duncan's post hoc tests was adopted to determine any significant difference among treatment groups. The mean and standard deviation were reported, and $P$ value of $<0.05$ was considered statistically significant. A linear regression model was used to determine the relationship between the density value of MRJP1 band on SDS-PAGE gel and MRJP1 concentrations measured by ELISA in RJ. 


\section{Results}

\subsection{Identification of specific regional peptide of MRJP1}

The alignment of amino acid sequences of the nine members of the MRJP family (Fig. 1) showed high homology among them. MRJP1-5 share at least 10 regions with 3-5 identical amino acid residue sequences; MRJP1-9 share at least 7 regions with 3-4 identical amino acid residue sequences. This suggests that the anti-MRJP1 antibody raised with full length MRJP1 might recognize all MRJP family members. Through multi-alignment analysis, we identified four peptides with more than three unique amino acid residues, which are quite different from the corresponding regions of MRJP2-9 members: QDAILSG corresponding to region 51-57, HDKIFVTM to region 73-80, NIRTVAQ to region 340-346, and IKEALPHVPIFD to region 359-370 of MRJP1 (Fig. 1). The longest peptide $\mathrm{M} 1$, with 12 residues at region 359-370 (IKEALPHVPIFD; Fig. 1), was selected as the region unique to MRJP1 for synthesizing the specific peptide.

\subsection{Specific properties of anti-SP-MRJP1 anti- body and anti-R-MRJP1 antibody}

SDS-PAGE of MRJP1 isolated from fresh RJ by ultracentrifugation and antibody affinity showed that one protein band of about $57 \mathrm{kDa}$ (Fig. 2a) was identical to MRJP1 in size as previously reported (Simúth, 2001). In contrast, the fresh RJ showed more than four proteins including MRJP1, MRJP2, MRJP3,
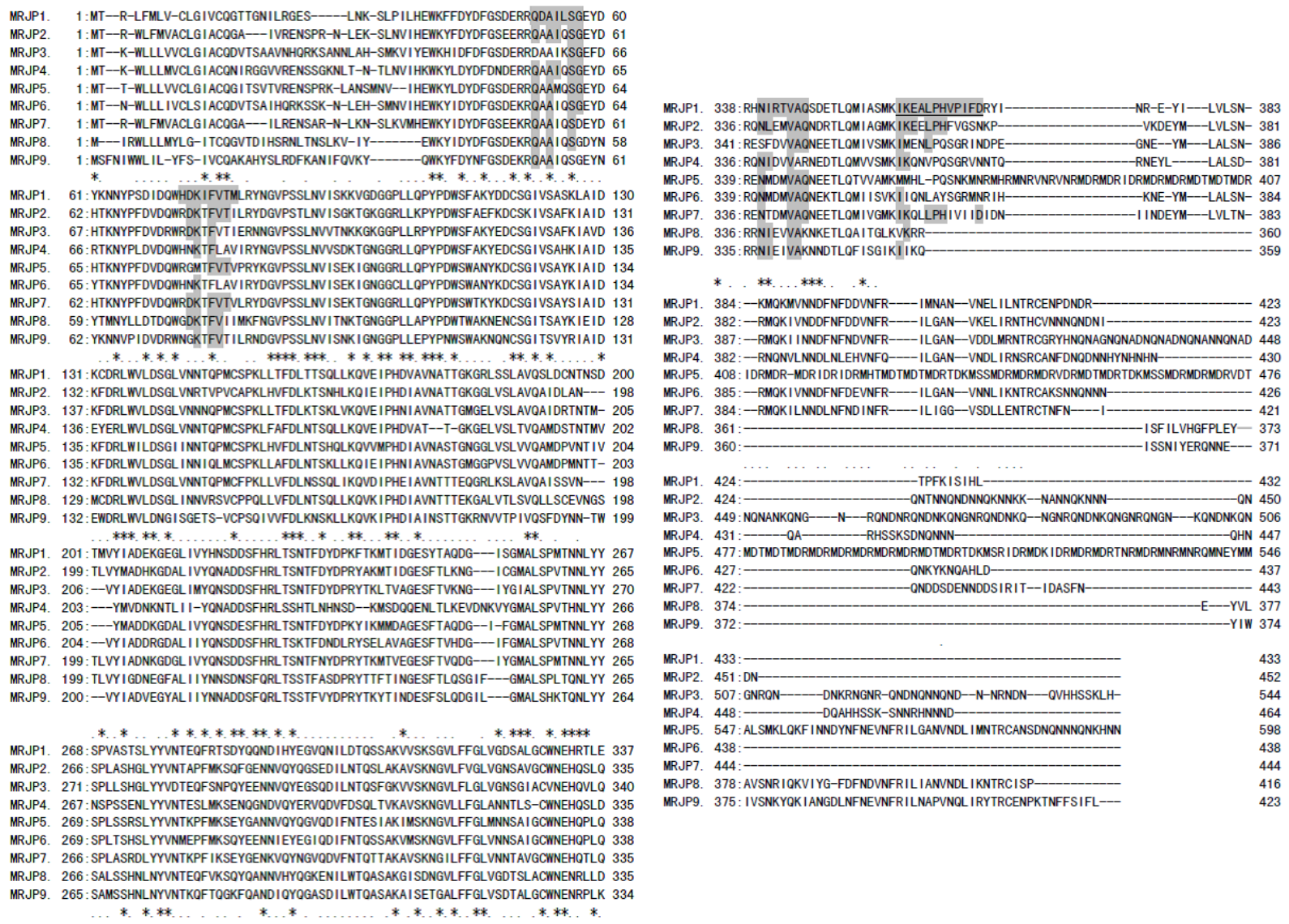

Fig. 1 Homology analysis of amino acid sequences encoded by MRJP1-9 genes of Apis mellifera

Conserved amino acid residues of the MRJP family were marked with asterisks under the amino acid residues of MRJP9. The specific amino acid residues of MRJP1 selected by homology analysis of the MRJP family are in gray. The peptide M1 with 12 residues at regions 359-370 designed for raised antibody is indicated by underlining. The sequence numbers of MRJP1-9 in GenBank are NM_001011579 (MRJP1), NM_001011580 (MRJP2), NM_001011601 (MRJP3), NM_001011610 (MRJP4), NM_001011599 (MRJP5), NM_001011622 (MRJP6), NM_001014429 (MRJP7), NM_001011564 (MRJP8), and NM_ 001024697 (MRJP9), respectively 
and MRJP5 with 25-87 kDa (Fig. 2a), which were reported previously (Simúth, 2001). More importantly, in Western blot assay, anti-SP-MRJP1 antibody recognized MRJP1 only in RJ (Fig. 2b), whereas anti-R-MRJP1 antibody bound to other members of the MRJP family (Fig. 3b) corresponding to the SDS-PAGE profile of MRJPs (Fig. 3a). This suggests that anti-R-MRJP1 antibody lacks specificity for MRJP1. This finding demonstrated that anti-SP-MRJP1 antibody is highly specific for MRJP1, and the purified natural MRJP1 proportion is suitable for use as the standard in RJ quality control.

\subsection{Binding activity of anti-SP-MRJP1 antibody}

The results in Table 1 illustrate the binding activities of anti-SP-MRJP1 antibody. The OD values of the antibody at 80000 -fold dilution were 10 times that of the unimmunized rabbit serum (OD at 1250-fold dilution). This suggests that the antibody possesses a very high binding activity to MRJP1. Our previous result showed that the binding activity of anti-R-

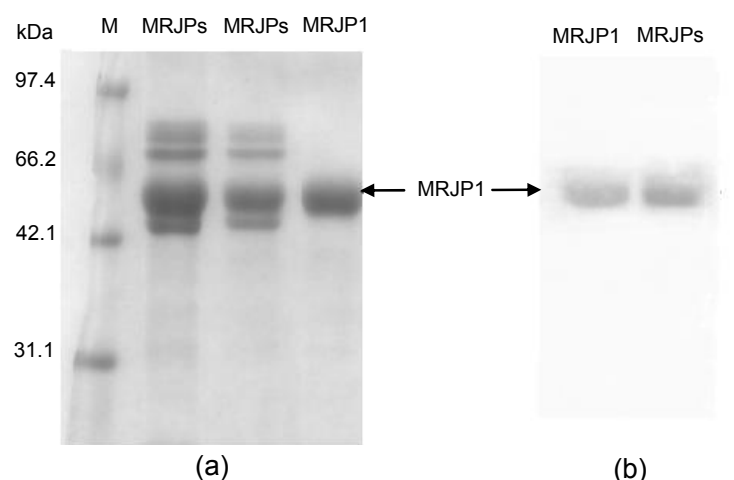

Fig. 2 SDS-PAGE (a) and Western blot analysis (b) of MRJPs probed with primary anti-SP-MRJP1 antibody Lanes: M, protein marker; MRJPs, soluble RJ proteins; MRJP1, purified natural MRJP1
MRJP1 antibody is 20000-fold dilution (Shen et al., 2010b), which is only one fourth of the binding activity of anti-SP-MRJP1 antibody.

\subsection{Thermal stability of MRJPs in RJ}

Degradation of MRJPs in RJ samples stored at $40{ }^{\circ} \mathrm{C}$ from 7 to $42 \mathrm{~d}$ was measured using SDS-PAGE (Fig. 4). We found that overall the key MRJP proteins (i.e., MRJP1, MRJP2, MRJP3, and MRJP5) in RJ stored at $40{ }^{\circ} \mathrm{C}$ from 7 to $42 \mathrm{~d}$, degraded consistently when compared with those of the fresh RJ $(0 \mathrm{~d})$. These findings suggest that not only MRJP1 but also other MRJP proteins are prone to degradation under thermal treatment.

\subsection{Standardization of ELISA with both antibodies}

Based on ELISA with both antibodies, we generated two calibration curves: $y=0.036 x+0.264$ $\left(R^{2}=0.993\right)$ for anti-SP-MRJP1 antibody (Fig. 5) and $y=0.1100 x+0.1239 \quad\left(R^{2}=0.998\right) \quad$ for anti-R-MRJP1 antibody in a concentration ranging from 0 to $10 \mathrm{~g} / \mathrm{ml}$ of MRJP1 in PBS, respectively.

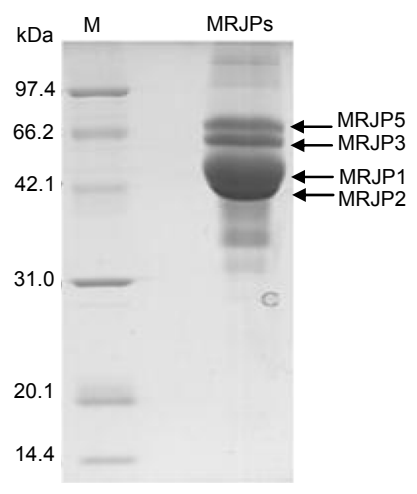

(a)

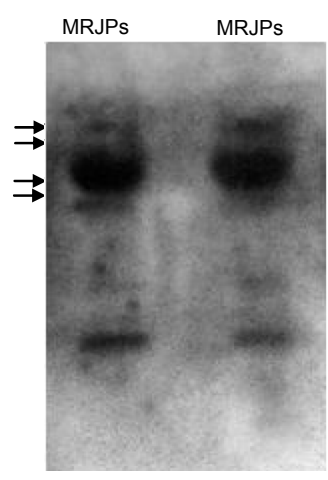

(b)
Fig. 3 SDS-PAGE (a) and Western blot analysis (b) of MRJPs probed with primary anti-R-MRJP1 antibody Lanes: M, protein marker; MRJPs, soluble RJ proteins

Table 1 Binding activity of anti-SP-MRJP1 antibody by ELISA

\begin{tabular}{|c|c|c|c|c|c|c|c|c|}
\hline \multirow{3}{*}{ Sample } & \multicolumn{8}{|c|}{ OD value at $450 \mathrm{~nm}$} \\
\hline & \multicolumn{7}{|c|}{ Dilution fold of anti-SP-MRJP1 antibody } & \multirow{2}{*}{$\begin{array}{l}\mathrm{CK} \text { at } 1250 \text {-fold } \\
\text { dilution }\end{array}$} \\
\hline & 1250 & 2500 & 5000 & 10000 & 20000 & 40000 & 80000 & \\
\hline 1 & 2.376 & 2.375 & 2.375 & 2.368 & 2.071 & 1.233 & 0.637 & 0.071 \\
\hline 2 & 2.375 & 2.375 & 2.375 & 2.376 & 2.375 & 2.184 & 1.611 & 0.068 \\
\hline
\end{tabular}

CK: serum from normal rabbits 


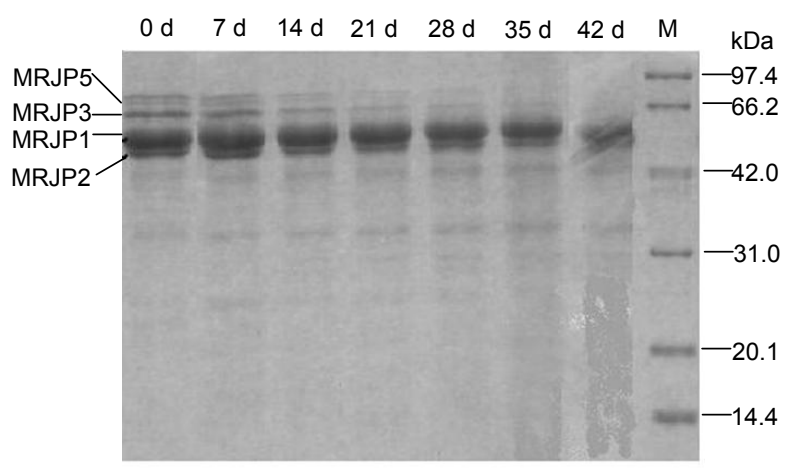

(a)

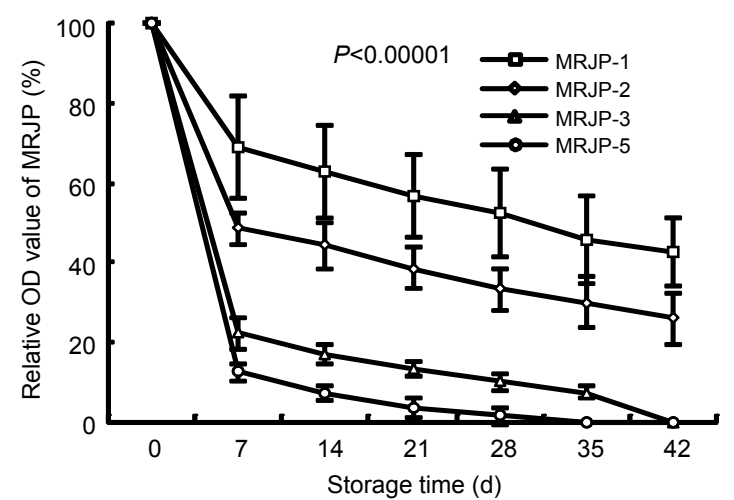

(b)

Fig. 4 Degradation analysis of MRJPs in RJ using gel documentation system

(a) SDS-PAGE analysis of RJ proteins stored at $40{ }^{\circ} \mathrm{C}$ from 0 to $42 \mathrm{~d}$. Lanes of $0,7,14,21,28,35$, and $42 \mathrm{~d}$ refer to the RJ proteins stored at $40{ }^{\circ} \mathrm{C}$ from 0 to $49 \mathrm{~d}$, respectively; Lane $\mathrm{M}$ refers to protein marker. (b) Degradation analysis of MRJPs in RJ. Relative OD value of MRJPs refers to the ratio of the OD of interest protein band in object RJ (7, 14, 21, 28, 35, and $42 \mathrm{~d}$ ) relative to the $\mathrm{OD}$ of interest protein band in fresh $\mathrm{RJ}(0 \mathrm{~d})$. The OD of interest protein band in fresh RJ was regarded as $100 \%$. Data are expressed as mean $\pm \operatorname{SD}(n=3)$

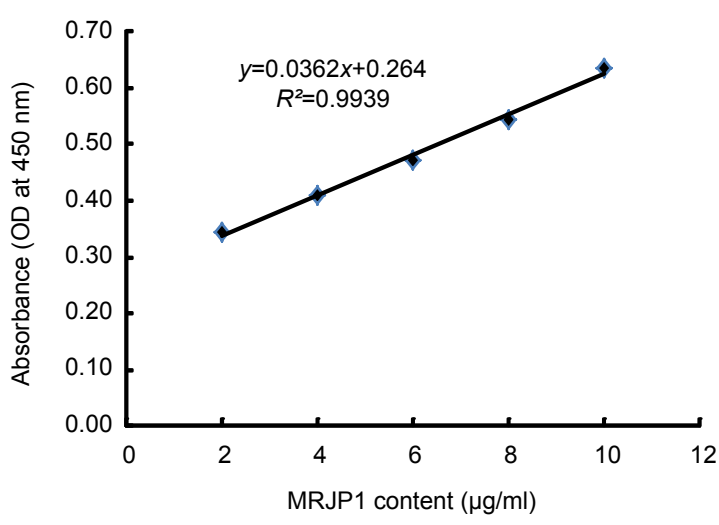

Fig. 5 Calibration curve of MRJP1 in PBS solution The calibration curve from 2 to $10 \mu \mathrm{g} / \mathrm{ml}$ of MRJP1 in PBS was used for MRJP1 determination in 100-fold dilutions of RJ samples. The curves were prepared in triplicate for standard concentration

\subsection{Comparisons of the specificity and sensitivity of both antibodies to MRJP1}

ELISA results with anti-R-MRJP1 and anti-SPMRJP1 antibodies showed different quantities of MRJP1 in the same RJ samples. The protein contents for RJ samples obtained with anti-R-MRJP1 antibody and anti-SP-MRJP1 antibody were $(10.8 \pm 1.0) \%$ and $(5.9 \pm 0.2) \%$, respectively. The value $(10.8 \pm 1.0) \%$ is consistent with the contents of MRJPs and MRJP1 for fresh RJ in previous reports, which showed fresh RJ contains $12 \%-15 \%$ crude proteins, of which about $80 \%$ are MRJPs (Furusawa et al., 2008).
As demonstrated in Western blot analysis, anti-RMRJP1 antibody bound to almost all members of MRJPs in RJ; this value (10.8\%) measured by anti-R-MRJP1 antibody is an overestimate of MRJP1 protein in the fresh RJ. On the other hand, the value of 5.9\% measured using ELISA with anti-SP-MRJP1 antibody is an accurate amount of MRJP1 in RJ, as MRJPs usually contains more than 45\% MRJP1 (Furusawa et al., 2008). Therefore, we consider that quantification of MRJP1 using ELISA with anti-SPMRJP1 antibody is a reliable method.

\subsection{Degradation of MRJP1 in RJ during storage}

The concentration of total protein in fresh $\mathrm{RJ}$ was determined as $(15.2 \pm 0.1) \%$ using nitrogen Kjeldahl assay. Then, the content of MRJP1 in total protein of RJ samples stored at $40{ }^{\circ} \mathrm{C}$ from 0 to $49 \mathrm{~d}$ was estimated by measuring the density value of the MRJP1 band on SDS-PAGE (Fig. 6a), and quantitatively analyzed by ELISA using anti-SP-MRJP1 antibody (Fig. 6b). ELISA showed that the MRJP1 content of the total protein of RJ stored at $40{ }^{\circ} \mathrm{C}$ for 7 , $14,21,28,35,42$, and $49 \mathrm{~d}$ decreased by $37.3 \%$, $55.9 \%, 58.0 \%, 60.6 \%, 65.7 \%, 72.7 \%$, and $73.1 \%$ $(n=3)$, respectively, relative to the MRJP1 content in the fresh $\mathrm{RJ}$ at $0 \mathrm{~d}(P<0.0001$; Fig. 7). The relationship between the density value of MRJP1 and the MRJP1 content (measured by ELISA using antiSP-MRJP1 antibody) in the total protein of RJ is given in Fig. 6c. The ELISA quantitation of MRJP1 in 
the total protein of $\mathrm{RJ}$ ranging from $5 \%$ to $30 \%$ was strongly and positively correlated with the density values of MRJP1 bands on the SDS-PAGE gel of RJ $\left(R^{2}=0.972, P<0.0001\right)$. These findings suggest that the ELISA method measuring MRJP1 with antiSP-MRJP antibody is a reliable tool for determining freshness and authenticity of RJ.

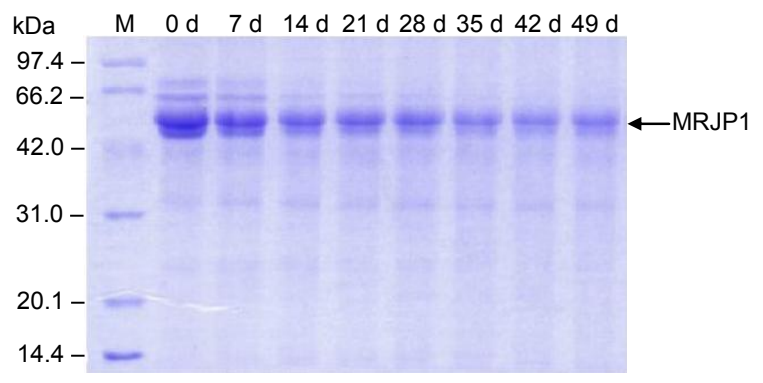

(a)

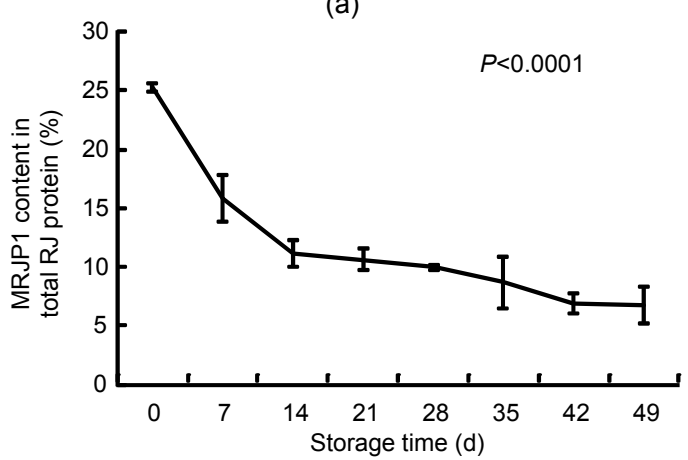

(b)

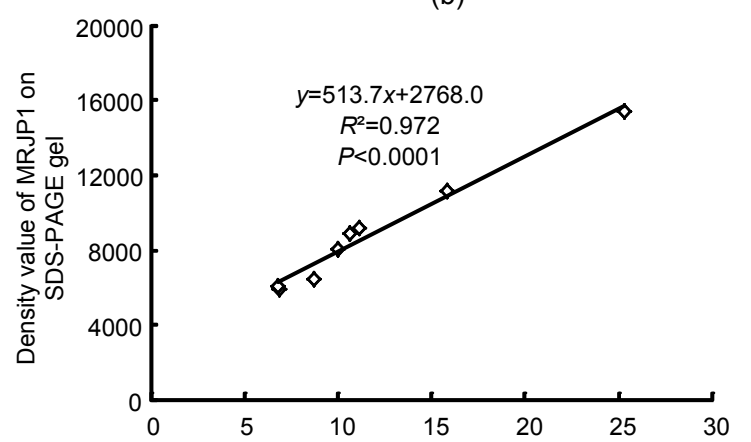

MRJP1 content in total RJ protein obtained via ELISA (\%)

(c)

Fig. 6 Degradation analysis of MRJP1 in RJ using ELISA (a) SDS-PAGE analysis of RJ proteins stored at $40^{\circ} \mathrm{C}$ from 0 to $49 \mathrm{~d}$. Lanes of $0,7,14,21,28,35,42$, and $49 \mathrm{~d}$ refer to $\mathrm{RJ}$ proteins stored at $40{ }^{\circ} \mathrm{C}$ from $0 \mathrm{~d}$ to $49 \mathrm{~d}$, respectively; Lane $\mathrm{M}$ refers to protein marker. (b) Comparison of MRJP1 content in total protein (\%) of RJ stored at $40{ }^{\circ} \mathrm{C}$ from 0 to $49 \mathrm{~d}$ using ELISA. Data are expressed as mean $\pm \mathrm{SD}(n=3)$. (c) The correlation between the density value of the MRJP1 band on SDS-PAGE gel of RJ obtained via ImageJ program and the MRJP1 content in total protein of RJ samples measured by the ELISA method with anti-SP-MRJP1 antibody for RJ samples that were stored at $40{ }^{\circ} \mathrm{C}$ from 0 to $49 \mathrm{~d}$

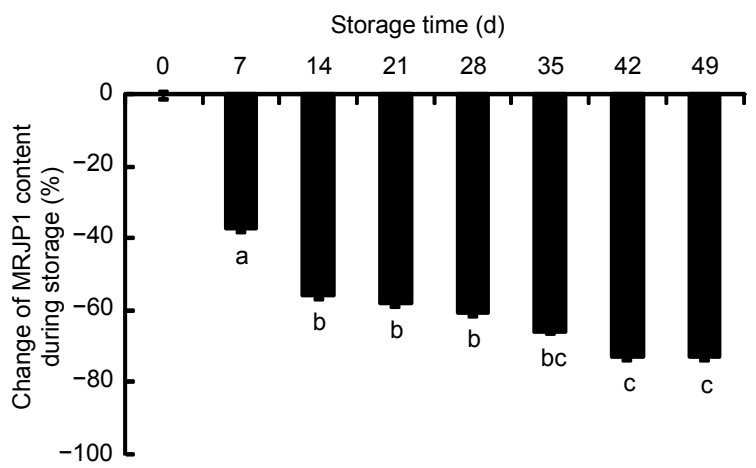

Fig. 7 Change of MRJP1 content in total protein of RJ during storage at $40{ }^{\circ} \mathrm{C}$ from 7 to $49 \mathrm{~d}$

The change value (\%) refers to the ratio of the MRJP1 content in total protein in object RJ sample (from 7 to $49 \mathrm{~d}$ ) relative to the MRJP1 content of total protein in fresh RJ $(0 \mathrm{~d})$ control. The same letter marked at column stands for no significant difference $(P>0.01)$. Data are expressed as mean $\pm \mathrm{SD}(n=3)$

\section{Discussion}

In this study, we have successfully developed a new antibody, anti-SP-MRJP1, based on a unique peptide selected from the protein sequence of MRJP1. Western blot analysis demonstrated that this antibody binds specifically to MRJP1 only in RJ, in contrast to the previously reported anti-R-MRJP1 antibody that binds to almost all members of MRJP family (Li Y. et al., 2008). Thus, the ELISA method based on anti-RMRJP1 antibody overestimated protein content of MRJP1 in RJ when compared with that based on ELISA with anti-SP-MRJP1 antibody. In addition, the anti-SP-MRJP1 antibody has a four-fold higher binding activity than anti-R-MRJP1 antibody. ELISA test of RJ using anti-SP-MRJP1 antibody can detect accurately the degradation of MRJP1 in RJ during the storage period of $49 \mathrm{~d}$ at $40{ }^{\circ} \mathrm{C}$. SDS-PAGE analysis of those RJ samples demonstrated a similar phenomenon. Our results demonstrated that the antiSP-MRJP1 antibody established in this study is highly specific for MRJP1.

RJ may spoil and lose its biological activities depending on storage duration and temperature. In order to preserve its biological properties, RJ has to be stored under freezing conditions (Zheng et al., 2011). Therefore, it is essential to measure RJ freshness to ensure its quality for trade. Inappropriate storage of 
RJ will be accompanied by acceleration of the Maillard browning reaction (Chen and Chen, 1995) and change of various physical and chemical properties including viscosity, titratable acidity, color, enzymatic activity, as well as the contents of MRJPs and free amino acids (Kamakura et al., 2001c). The compositional changes during storage at high temperature are not influenced by microorganisms and seem to be attributable to chemical and enzymatic activities. Interestingly, the degradation of MRJP1 in $\mathrm{RJ}$ was positively related to both storage temperature and storage period (Kamakura et al., 2001b; 2001c; Kamakura, 2011; Li J.K. et al., 2008). The results of native PAGE analysis for RJ stored at 4 and $40{ }^{\circ} \mathrm{C}$ showed that the two proteins in RJ, MRJP1 and MRJP2, were especially degraded when RJ was stored at $40{ }^{\circ} \mathrm{C}$ (Kamakura et al., 2001c). Furthermore, $\mathrm{RJ}$ stored at $40{ }^{\circ} \mathrm{C}$ for $7 \mathrm{~d}$ lost its activity for enhancing proliferation of rat hepatocytes, which was considered to be associated with degradation of MRJP1 (Kamakura et al., 2001b). According to two-dimensional PAGE, the amount of protein spots of MRJPs in fresh and $-20{ }^{\circ} \mathrm{C}$ stored RJ was more than that in RJ samples stored at $4{ }^{\circ} \mathrm{C}$ and at room temperature for one year. The quantity of MRJP1 decreased significantly following the temperature trend in all images (Li J.K. et al., 2008). Therefore, MRJP1 is a typical marker for measuring freshness of RJ. Based on these findings, RJ heated at $40{ }^{\circ} \mathrm{C}$ for $40 \mathrm{~d}$ was used as the control to investigate the activity of MRJP1 for inducing the differentiation of honeybee larvae into queens (Kamakura, 2011). The presence of MRJP1 was also suggested as a promising parameter for evaluation of RJ authenticity in quality and standardization of RJ (Sabatini et al., 2009).

The anti-MRJP1 antibody generated with natural MRJP1 from RJ could recognize at least three MRJP members (MRJP1, MRJP3, and one 128-kDa MRJP member) in hypopharyngeal gland homogenates. In this investigation, the anti-MRJP1 antibody was generated with natural MRJPs as antigen, then separated by SDS-PAGE, and excised and electrotransferred on to an NC. Bioinformatics analyses on the analogous antigenic regions among MRJPs showed that MRJP1, MRJP2, and MRJP3 have more than $44 \%$ identity, and MRJP1-5 proteins share seven antigenic conserved regions corresponding to the epitopes for the anti-MRJP1 antibody (Peixoto et al.,
2009). The identities among MRJP sequences were suggested by hybridization assay and sequence alignment (Schmitzová et al., 1998; Albert et al., 1999; Drapeau et al., 2006; Peixoto et al., 2009). This antibody recognizes MRJP family members in the denatured protein. In addition, sequence analysis of all of the MRJP family members contains an $\mathrm{N}$-terminal hydrophobic sequence that would function as a cleavable signal peptide as well as a putative N-linked glycosylation site (Drapeau et al., 2006; Peixoto et al., 2009; Klaudiny et al., 2010). Yamaguchi et al. (2013) were the first to determine MRJP1 levels in RJ samples from different companies with specific MRJP1 antibody. However, as a novel method, this article lacked essential information and details such as how to design peptide specific for MRJP1, purification of antibody, its difference from anti-R-antibody, and application in RJ freshness determination required by apiculture.

ELISA has been used as a rapid diagnostic tool in medicine, toxicology, as well as in quality-control in various industries around the world (Kajiura et al., 2008). Its accuracy is dependent upon the antigen used to create the polyclonal antibody. Special peptide immunogens are often used to generate polyclonal antibodies that target unique epitopes, especially for protein families of high homology (Shinnick et al., 1983; Lequin, 2005). Such antibodies are directed against a specific region of the protein chosen in advance by the investigator and so have a predetermined specificity (Huesca et al., 2000). ELISA with antiR-MRJP1 antibody was used in quantification of MRJP1 in honeybees (Bíliková and Simúth, 2010). However, based on the observation in our study, the anti-R-MRJP1 antibody bound non-specifically to many members of the MRJP1 family because of common homology. Thus, ELISA with the anti-RMRJP1 antibody may not be suitable for determining the freshness of RJ, but it may be used to measure the total content of the MRJP family

$\mathrm{RJ}$ adulteration is the most important problem affecting quality. Many studies on 10-10-HDA content (Kamakura et al., 2001c), the ratios of the stable isotopes of the elements $\mathrm{C}$ and $\mathrm{N}$, the fatty acid composition (Sabatini et al., 2009) concerned with authenticity, qualification, and standardization of RJ have been carried out. Many indices to measure RJ freshness related to moisture, protein, total sugar, 
acidity levels and superoxide dismutase activity (Zheng et al., 2011), chromogenic reaction with $\mathrm{HCl}$ (Zheng et al., 2012), furosine (Messia et al., 2005), and changes in the content of amino acids (Wu et al., 2009) have been proposed. However, these indices either lack reliability as they are influenced by various factors or require complex sample preparation and expensive equipment, such HPLC for quantification. Thus, these indices are not widely accepted. MRJP1, the single specific protein and key factor of RJ associated with its biological activities as the unique marker of RJ freshness, has attracted much attention (Kamakura et al., 2001c; Sabatini et al., 2009; Yamaguchi et al., 2013). Moreover, compared with other methods described above, ELISA method developed by us has several advantages, including high reliability, lower cost, and ease-of-use.

In conclusion, we demonstrated that the anti-SPMRJP1 antibody generated using a unique synthetic regional peptide corresponding to MRJP1 protein sequence as antigen is highly specific for MRJP1 in RJ. With this antibody, the quantification of MRJP1, the RJ freshness marker, is accurately determined. It is anticipated that such a method for measuring MRJP1 will be used as a reliable tool for determining the freshness and authenticity of RJ, and for detection of MRJP1 expression in honeybee tissues by using specific antibodies in the near future.

\section{Acknowledgements}

The authors are grateful to Prof. Chuan-xi ZHANG and Mr. Zheng-xian CHEN (Zhejiang University, China) for their technical assistance, Dr. Liang LIU (the University of Georgia, USA) for his help with statistical analysis, and Dr. Chao-Qiang LAI (JM-USDA HNRCA at Tufts University, USA) for editing the manuscript.

\section{Compliance with ethics guidelines}

Li-rong SHEN, Yi-ran WANG, Liang ZHAI, Wen-xiu ZHOU, Liang-liang TAN, Mei-lu LI, Dan-dan LIU, and Fa XIAO declare that they have no conflict of interest.

This article does not contain any studies with human or animal subjects performed by any of the authors.

\section{References}

Albert, S., Klaudiny, J., 2004. The MRJP/YELLOW protein family of Apis mellifera: identification of new members in the EST library. J. Insect Physiol., 50(1):51-59. [doi:10. 1016/j.jinsphys.2003.09.008]

Albert, S., Bhattacharya, D., Klaudiny, J., et al., 1999. The family of major royal jelly proteins and its evolution. $J$.
Mol. Evol., 49(2):290-297. [doi:10.1007/PL00006551]

Antinelli, J.F., Zeggane, S., Davico, R., et al., 2003. Evaluation of $(E)$-10-hydroxydec-2-enoic acid as a freshness parameter for royal jelly. Food Chem., 80(1):85-89. [doi:10. 1016/S0308-8146(02)00243-1]

AQSIQ (General Administation of Quality Supervision, Inspection and Quarantine of the People's Republic of China), 2008. GB 9697-2008: The Quality Standard of Royal Jelly. National Standard of People's Republic of China, China Standard Press (in Chinese).

Bíliková, K., Simúth, J., 2010. New criterion for evaluation of honey: quantification of royal jelly protein apalbumin 1 in honey by ELISA. J. Agric. Food Chem., 58(15):87768781. [doi:10.1021/jf101583s]

Chen, C., Chen, S.Y., 1995. Changes in protein components and storage stability of royal jelly under various conditions. Food Chem., 54(2):195-200. [doi:10.1016/03088146(95)00031-D]

Drapeau, M.D., Albert, S., Kucharski, R., et al., 2006. Evolution of the yellow/major royal jelly protein family and the emergence of social behavior in honey bees. Genome Res., 16(11):1385-1394. [doi:10.1101/gr5012006]

Fontana, R., Mendes, M.A., DeSouza, B.M., et al., 2004. Jelleines: a family of antimicrobial peptides from the royal jelly of honeybees (Apis mellifera). Peptides, 25(6): 919-928. [doi:10.1016/j.peptides.2004.03.016]

Fujii, A., Kobayashi, S., Kuboyama, N., et al., 1990. Augmentation of wound healing by royal jelly (RJ) in streptozotocin-diabetic rats. Jpn. J. Pharmacol., 53(3): 331-337. [doi:10.1254/jjp.53.331]

Fujiwara, S., Imai, J., Fujiwara, M., et al., 1990. A potent antibacterial protein in royal jelly. J. Biol. Chem., 265(19): 11333-11337.

Furusawa, T., Rakwal, R., Nam, H.W., et al., 2008. Comprehensive royal jelly (RJ) proteomics using one- and two-dimensional proteomics platforms reveals novel RJ proteins and potential phospho/glycoproteins. J. Proteome Res., 7(8):3194-3229. [doi:10.1021/pr800061j]

Hanes, J., Simúth, J., 1992. Identification and partial characterization of major royal jelly protein of honey bee (Apis mellifera L.). J. Apic. Res., 31(1):22-26.

Honda, Y., Fujita, Y., Maruyama, H., et al., 2011. Lifespanextending effects of royal jelly and its related substances on the nematode Caenorhabditis elegans. PLOS ONE, 6(8):e23527. [doi:10.1371/journal.pone.0023527]

Howe, S.R., Dimick, P.S., Benton, A.W., 1985. Composition of freshly harvested and commercial royal jelly. J. Agric. Res., 24(1):52-61.

Huesca, M., Sun, Q., Peralta, R., et al., 2000. Synthetic peptide immunogens elicit polyclonal and monoclonal antibodies specific for linear epitopes in the D motifs of Staphylococcus aureus fibronectin-binding protein, which are composed of amino acids that are essential for fibronectin binding. Infect. Immun., 68(3):1156-1163. [doi:10.1128/ IAI.68.3.1156-1163.2000]

Inoue, S., Koya-Miyata, S., Ushio, S., et al., 2003. Royal jelly 
prolongs the life span of $\mathrm{C} 3 \mathrm{H} / \mathrm{HeJ}$ mice: correlation with reduced DNA damage. Exp. Gerontol., 38(9):965-969. [doi:10.1016/S0531-5565(03)00165-7]

Kajiura, S., Yashiki, T., Funaoka, H., et al., 2008. Establishment and characterization of monoclonal and polyclonal antibodies against human intestinal fatty acid-binding protein (I-FABP) using synthetic regional peptides and recombinant I-FABP. J. Immunoassay Immunochem., 29(1):19-41. [doi:10.1080/153218107017 35005]

Kamakura, M., 2011. Royalactin induces queen differentiation in honeybees. Nature, 473(7348):478-483. [doi:10.1038/ nature 10093]

Kamakura, M., Mitani, N., Fukuda, T., et al., 2001a. Antifatigue effect of fresh royal jelly in mice. J. Nutr. Sci. Vitaminol., 47(6):394-401. [doi:10.3177/jnsv.47.394]

Kamakura, M., Suenobu, N., Fukushima, M., 2001b. Fiftyseven-kDa protein in royal jelly enhances proliferation of primary cultured rat hepatocytes and increases albumin production in the absence of serum. Biochem. Biophys. Res. Commun., 282(4):865-874. [doi:10.1006/bbrc.2001. 4656]

Kamakura, M., Fukuda, T., Fukushima, M., et al., 2001c. Storage-dependant degradation of 57-kDa protein in royal jelly: a possible marker for freshness. Biosci. Biotechnol. Biochem., 65(2):277-284. [doi:10.1271/bbb.65.277]

Klaudiny, J., Hanes, J., Kulifajova, J., et al., 2010. Molecular cloning of two cDNA from the heads of the nurse honey bee (Apis mellifera L.) for coding related proteins of royal jelly. J. Apicul. Res., 33(2):105-111.

Kohno, K., Okamotom, I., Sanom, O., et al., 2004. Royal jelly inhibits the production of proinflammatory cytokines by activated macrophages. Biosci. Biotechnol. Biochem., 68(1):138-145. [doi:10.1271/bbb.68.138]

Lequin, R.M., 2005. Enzyme immunoassay (EIA)/enzymelinked immunosorbent assay (ELISA). Clin. Chem., 51(12):2415-2418. [doi:10.1373/clinchem.2005.051532]

Li, J.K., Feng, M., Zhang, L., et al., 2008. Proteomics analysis of major royal jelly protein changes under different storage conditions. J. Proteome Res., 7(8):3339-3353. [doi:10.1021/pr8002276]

Li, Y., Chen, Y.X., Shen, L.R., et al., 2008. Prokaryotic expression of mrjp 7 of Apis cerana cerana and preparation of its polyclonal antibody. J. Shanghai Jiaotong Univ. (Agric. Sect.), 26(2):109-113 (in Chinese).

Majtan, J., Kovacova, E., Blikova, K., et al., 2006. The immunostimulatory effect of the recombinant apalbumin 1-major honeybee royal jelly protein-on TNF $\alpha$ release. Intern. Immunol. Pharmacol., 6(2):269-278. [doi:10. 1016/j.intimp.2005.08.014]

Malecová, B., Ramserb, J., O'Brienb, J.K., et al., 2003. Honeybee (Apis mellifera L.) mrjp gene family: computational analysis of putative promoters and genomic structure of mrjpl, the gene coding for the most abundant protein of larval food. Gene, 303:165-175. [doi:10.1016/ S0378-1119(02)01174-5]

Matsui, T., Yukiyoshi, A., Doi, S., et al., 2002. Gastrointestinal enzyme production of bioactive peptides from royal jelly protein and their antihypertensive ability in SHR. J. Nutr. Biochem., 13(2):80-86. [doi:10.1016/S0955-2863(01)00 198-X]

Messia, M.C., Caboni, M.F., Marconi, E., 2005. Storage stability assessment of freeze dried royal jelly by furosine determination. J. Agric. Food Chem., 53(11):4440-4443. [doi:10.1021/jf0404647]

Peixoto, L.G., Calabria, L.K., Garcia, L., et al., 2009. Identification of major royal jelly proteins in the brain of the honeybee Apis mellifera. J. Insect Physiol., 55(8): 671-677. [doi:10.1016/j.jinsphys.2009.05.005]

Sabatini, A.G., Marcazzan, G.L., Caboni, M.F., et al., 2009. Quality and standardisation of royal jelly. J. ApiProd. ApiMed. Sci., 1(1):1-6. [doi:10.3896/IBRA.4.01.1.04]

Salazar-Olivo, L.A., Paz-Gonzales, V., 2005. Screening of biological activities present in honeybee (Apis mellifera) royal jelly. Toxicol. in Vitro, 19(5):645-651. [doi:10. 1016/j.tiv.2005.03.001]

Sambrook, J., Fritsch, E.F., Maniatis, T., 1989. Molecular Cloning: A Laboratory Manual, 2nd Ed. Cold Spring Harbor Laboratory Press, Cold Spring Harbor, NY, USA.

Schmitzová, J., Klaudiny, J., Albert, S., et al., 1998. A family of major royal jelly proteins of the honeybee Apis mellifera L. Cell. Mol. Life Sci., 54(9):1020-1030. [doi:10. 1007/s000180050229]

Shen, L.R., Ding, M.H., Zhang, L.W., et al., 2010a. Expression of Acc-royalisin gene from royal jelly of Chinese honeybee in Escherichia coli and its antibacterial activity. $J$. Agric. Food Chem., 58(4):2266-2273. [doi:10.1021/ jf902574t]

Shen, L.R., Zhang, W.G., Jin, F., et al., 2010b. Expression of recombinant AccMRJP1 protein from royal jelly of Chinese Honeybee in Pichia pastoris and its proliferation activity in an insect cell line. J. Agric. Food Chem., 58(16):9010-9017. [doi:10.1021/jf1007133]

Shinnick, T.M., Sutcliffe, J.G., Green, N., et al., 1983. Synthetic peptide immunogens as vaccines. Annu. Rev. Microbiol., 37(1):425-446. [doi:10.1146/annurev.mi.37. 100183.002233]

Simúth, J., 2001. Some properties of the main protein of honeybee (Apis mellifera) royal jelly. Apidologie, 32(1): 69-80. [doi:10.1051/apido:2001112]

Tamura, T., Fujii, A., Kuboyama, N., 1987. Antitumor effect of royal jelly. Folia Pharmacol. Japon., 89(2):73-80 (in Japanese). [doi:10.1254/fpj.89.73]

Tokunaga, K., Yoshida, C., Suzuki, K., et al., 2004. Antihypertensive effect of peptides form royal jelly in spontaneously hypertensive rats. Biol. Pharm. Bull., 27(2): 189-192. [doi:10.1248/bpb.27.189]

Wu, L.M., Zhou, J.H., Xue, X.F., et al., 2009. Fast determination of 26 amino acids and their content changes in royal jelly during storage using ultra-performance liquid chromatography. J. Food Compost. Anal., 22(3):242-249. [doi:10.1016/j.jfca.2008.10.022]

Yamaguchi, K., He, S., Li, Z., et al., 2013. Quantification of 
major royal jelly protein 1 in fresh royal jelly by indirect enzyme-linked immunosorbent assay. Biosci. Biotechnol. Biochem., 77(6):1310-1312. [doi:10.1271/bbb.130013]

Zheng, H.Q., Hu, F.L., Dietemann, V., 2011. Changes in composition of royal jelly harvested at different times: consequences for quality standards. Apidologie, 42(1): 39-47. [doi:10.1051/apido/2010033]

Zheng, H.Q., Wei, W.T., Wu, L.M., et al., 2012. Fast determination of royal jelly freshness by a chromogenic reaction. J. Food Sci., 77(6):S247-S252. [doi:10.1111/j.17503841.2012.02726.x]

\section{中文概要}

题 目: 用高度特异性王浆主蛋白 1 多克隆抗体 ELISA 法检测蜂王浆新鲜度

目 的: 为蜂王浆主蛋白 1（MRJP1）的快速检测和鉴别 提供科学依据, 为蜂王浆的质量控制提供技术 支持。

创新点: 首次比较了 MRJP1 特异性多克隆抗体与 MRJP1
重组表达蛋白多克隆抗体对王浆主蛋白家族的 免疫反应差异, 验证了蜂王浆中 MRJP1 蛋白降 解与保温时间的相关性, 建立了以 MRJP1 作为 蜂王浆新鲜度生物标志物的快速检测方法。

方 法: 通过蜂王浆主蛋白家族蛋白的氨基酸序列同源性 分析, 篮选出 MRJP1 的特异性多肽区域, 进行 人工合成, 免疫兔子后取血清制备成特异性多克 隆抗体。用蛋白质印迹法（Western blot）检测了 MRJP1 特异性多克隆抗体与 MRJP1 重组表达蛋 白多克隆抗体对王浆主蛋白家族的免疫反应。以 新鲜蜂王浆为对照品, 用 MRJP1 特异性抗体酶 联接免疫吸附剂测定 (ELISA) 法和变性电泳胶 灰度扫描法分别测定保温 $\left(40^{\circ} \mathrm{C}\right) 7 \sim 49$ 天的蜂 王浆中 MRJP1 含量的变化, 并进行了相关性 分析。

结 论: MRJP1 的特异性抗体对 MRJP1 蛋白具有专一的 免疫识别特性, 可特异性地检测代表蜂王浆新鲜 度的 MRJP1 含量变化, 并鉴别蜂王浆的真伪。

关键词: 新鲜度; 蜂王浆; 王浆主蛋白 1 ; ELISA; 高度 特异性 